\title{
Effect of acquisition depth and precompression from probe and couplant on shear wave elastography in soft tissue: an in vitro and in vivo study
}

\author{
Xiuming Wang", Yue Hu\#, Jia'an Zhu, Junxue Gao, Si Chen, Fang Liu, Wenxue Li, Yiqun Liu, Bilig Ariun \\ Department of Ultrasound, Peking University People's Hospital, 11 Xizhimen South Street, Beijing 100044, China
}

"These authors contributed equally to this work.

Correspondence to: Jia'an Zhu. Department of Ultrasound, Peking University People's Hospital, 11 Xizhimen South Street, Beijing 100044, China. Email: zhujiaan@pkuph.edu.cn.

\begin{abstract}
Background: Shear wave elastography is a promising method to diagnose early musculoskeletal lesions. We aimed to explore the feasible depth and acceptable precompression applied by probe and couplant for soft tissues in the present system.

Methods: Ex-vivo muscles were evaluated at depths of $0.5-6 \mathrm{~cm}$ by 3 operators, using $1-5 \mathrm{~mm}$ couplant thickness and 0-3.0 $\mathrm{kPa}$ probe pressure. We compared the shear wave speed (SWS) and used intraclass correlation coefficients to assess reproducibility. In vivo skin and subcutaneous superficial fascia from volunteers were tested at depths ranging from $0.1-0.5 \mathrm{~cm}$ with $1-20 \mathrm{~mm}$ couplant thickness.

Results: The SWS of ex-vivo muscles varied and increased with depth, and could not be acquired at $6 \mathrm{~cm}$ because the shear wave failed to be detected. Furthermore, while the SWS of ex-vivo muscles were not affected by the couplant thickness, it was affected by probe pressure. Most cases demonstrated a satisfactory agreement degree of the intraoperator reproducibility (ICC, 0.81-0.95) and a substantial interoperator reproducibility $(\mathrm{ICC}>0.60$ ). Inter- and intra-operator reproducibility was better at a depth of $0.5-4 \mathrm{~cm}$ than at $5 \mathrm{~cm}$. In the in vivo study, when tissues within a $0.2 \mathrm{~cm}$ depth were evaluated, the $\mathrm{SWS}$ that was acquired using a couplant thickness of $>10 \mathrm{~mm}$ was different from that acquired using other thicknesses.
\end{abstract}

Conclusions: The SWS acquired at a depth of $\leq 3 \mathrm{~cm}$ with a suitable amount of couplant is recommended.

Keywords: Acquisition depth; pressure; shear wave elastography; soft tissue

Submitted Aug 25, 2019. Accepted for publication Jan 17, 2020.

doi: $10.21037 /$ qims.2020.01.15

View this article at: http://dx.doi.org/10.21037/qims.2020.01.15

\section{Introduction}

Shear wave elastography is a form of ultrasound elasticity imaging technology that has recently received increased attention for its clinical applications. It is a powerful, noninvasive method for qualitatively and quantitatively assessing the elasticity of soft tissue (1-7). Several studies have reported its importance in breast, thyroid, and prostate imaging, and fibrosis in liver pathology (8-12). Since the early 1990s, several researchers have focused on the musculoskeletal system, and shear wave elastography has gradually been used for examining clinical musculoskeletal diseases in recent years $(13,14)$. It is a promising method that can be used to diagnose early musculoskeletal lesions, contrary to the conventional ultrasound methods that may be insufficient in the early stage (15). However, its application in the evaluation of musculoskeletal tissue elasticity requires further research $(1,13)$. Skeletal muscles are anisotropic and heterogeneous, and the characteristic position of most skeletal muscles is relatively shallow, contrary to the other visceral organs. Additionally, their 
muscle structure is complex and susceptible to muscle state and body posture with variable muscle fiber lengths and directions, thereby complicating its analysis (15-18). Therefore, in vivo assessment of muscle elasticity is considerably difficult.

The shear wave speed (SWS) varies with acquisition depth $(1,16,17,19,20)$, the pressure applied by the probe and couplant $(21,22)$, and the operating physicians (18). Alfuraih $e t a l$. acquired measurements under varying depths from the vastus lateralis and pointed out that different acquisition depths may affect the reliability of shear wave elastography in muscles (21). Ewertsen et al. evaluated the influence of depth on SWS for 3 different muscles (the biceps brachii, the gastrocnemius, and the quadriceps) in vivo with Siemens Acuson S3000 Helx system and found that SWS and depth demonstrated a significant negative correlation (23). These studies have primarily focused on assessing the SWS differences within muscles in vivo. By measuring the SWS using an elasticity phantom with Aixplorer, ACUSON S3000, and EPIQ 5 system, and by applying both high and low-frequency transducers, it was also found that SWS was affected by the acquisition depth (1). However, the results of depth investigation from phantoms may not be generalized to muscles, as anisotropy may affect the propagation of shear waves in muscles. Alfuraih et al. compared the minimal probe pressure with a considerable amount of standoff gel layer (approximately $5 \mathrm{~mm}$ of gel visible on top of the images) and concluded that the measurements acquired using a minimal probe pressure without a standoff gel yielded the outcomes with the best reliability (21). The study further highlighted that the shear wave elastography of skeletal muscle was sensitive to transducer pressure, and a generous amount of coupling gel should be applied to prevent the probe from compressing the muscles (24). To the best of our knowledge, the previous studies did not recommend a suitable amount of couplant when measuring superficial soft tissues.

Furthermore, the reproducibility between different conditions and operators is of vital importance to compare the results in a future follow-up. Lacourpaille $e t$ al. specifically focused on the reproducibility assessments at various muscular sites and observed very good reliability (25). Cortez et al. assessed intra- and inter-operator reproducibility for a specific site in normal skeletal muscles and pointed out that inter- and intra-operator reproducibility was fair to good (intraclass correlation coefficients values between 0.40 and $0.74)(18)$.

Further standardization of the acquisition process will be essential in reducing the technically induced variation, thereby improving the measurement and diagnostic accuracy. In the present study, we used an isolated muscle as the object, focusing on the effect of acquisition depth and pressure applied by the probe and couplant on the SWS. To further explore the influence of pressure on tissues that are particularly superficial, we also measured the SWS of skin and subcutaneous superficial fascia of healthy people using different amounts of couplant.

We aimed to investigate the feasible depth and acceptable pressure applied by probe and couplant on soft tissues by determining their effect on the SWS in the given conditions and system. Furthermore, the intra- and inter-operator reproducibility of the mean SWS measurements with different depths and couplant thicknesses were evaluated.

\section{Methods}

\section{Subjects}

\section{Animals}

Twenty-eight freshly isolated muscle samples from healthy pork tenderloin prepared for consumption were examined at $20^{\circ} \mathrm{C}$ (room temperature) after being removed from the body no more than 6 hours prior. The mean size of each muscle was $15 \mathrm{~cm} \times 7 \mathrm{~cm} \times 7 \mathrm{~cm}$ and each demonstrated clear muscle fiber.

\section{Humans}

We selected 14 healthy volunteers, consisting of 5 males and 9 females. The participant group had the following values: mean age $=31$ (range, 22-54) years, mean body mass index $(B M I)=22.5$ (range, $18.3-23.66) \mathrm{kg} / \mathrm{m}^{2}$, weight $=63.5$ (range, 50-75) kg, and average height $=171$ (range, 166-183) $\mathrm{cm}$. All volunteers had their skin and subcutaneous superficial fascia of the front of the bilateral forearm examined in the resting position. While performing the examination, the volunteers were sitting on a chair with the forearm resting and were made to place their forearm flat on the examination bed with the elbow joint inflecting slightly. All participants were free of drugs, and those with a history of skin disease, systemic lesions involving the skin, upper extremity rash, scars, wounds, tumors (malignant or benign) of the upper-arm, or musculoskeletal or rheumatic conditions were excluded. The study was approved by the institutional ethics board of Peking University People's Hospital, and all participants gave informed consent. 

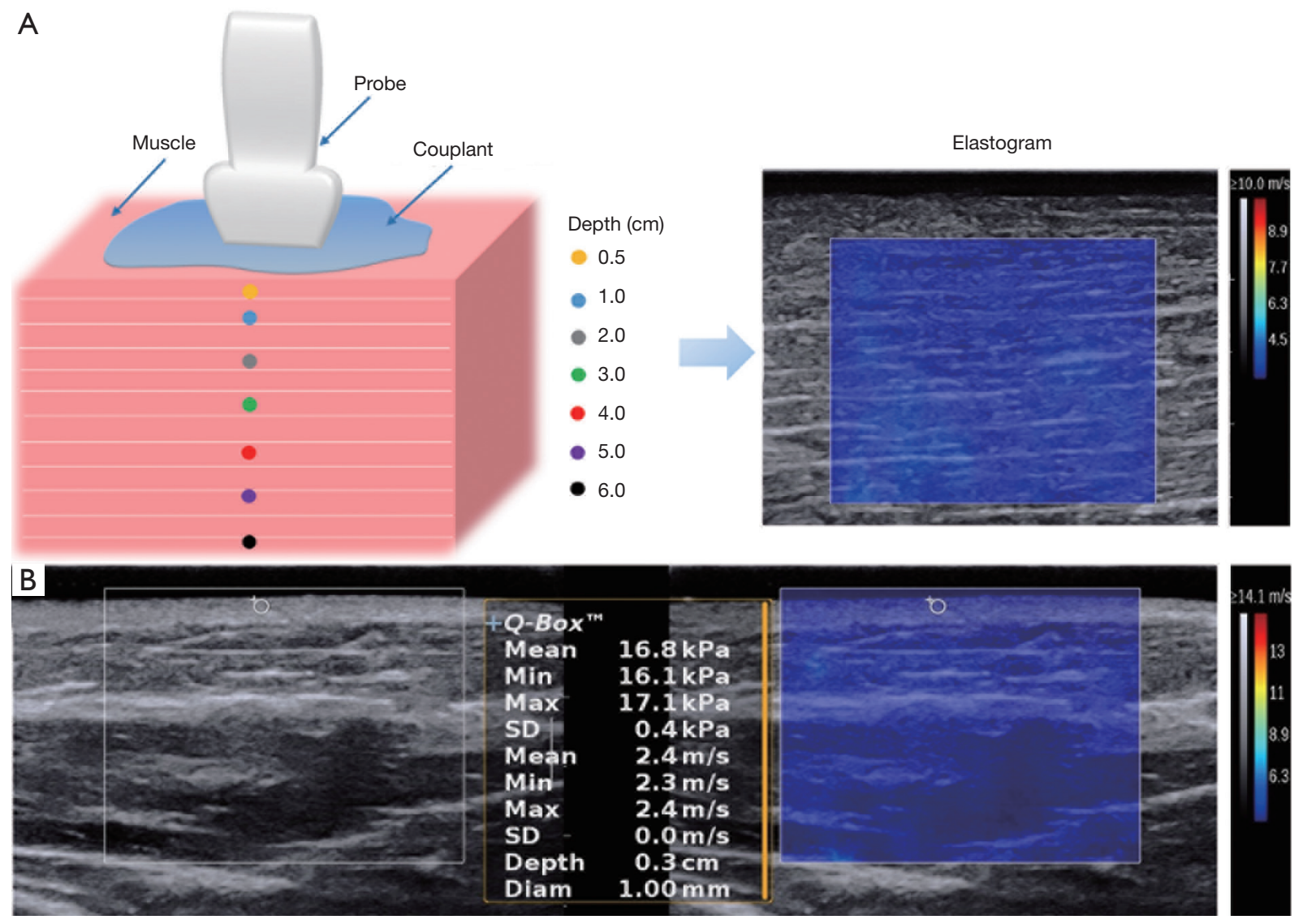

Figure 1 Schematic diagram of the shear wave elastography operating process for the ex-vivo study (A) and local speed map obtained from the skin and subcutaneous tissue with 2-mm couplant for the in-vivo study (B).

\section{Equipment}

The shear wave elastography measurements were acquired using the recent commercially released shear wave elastography package for the Aixplorer system (SuperSonic Imagine, Aix-en-Provence, France) that employs an SL102 high-frequency linear probe. This system operates with a spatial resolution of $1 \mathrm{~mm} \times 1 \mathrm{~mm}$ in elastography and $0.3 \mathrm{~mm} \times 0.3 \mathrm{~mm}$ in B-mode (18). For this system, the shear wave elastography uses the acoustic radiation force induced by ultrasound beams to stimulate underlying tissues. This pressure pushes the tissue in the direction of propagation to which the tissue subsequently reacts with a restoring force. This force produces shear waves that propagate transversely in the tissue. Each measurement included a rectangular box $(2.0 \mathrm{~cm} \times 2.5 \mathrm{~cm})$ to display the tissue stiffness in the shear wave elastography image using a semitransparent color overlay, as illustrated in Figure 1A. This could facilitate the prediction of the most probable shear wave speed and imaging quality before measurement. The measurements were recorded in SWS $(\mathrm{m} / \mathrm{s})$ considering the anisotropy of muscles, because Young's modulus (kPa) has been validated only in isotropic and homogeneous tissues (18). The units of $\mathrm{m} / \mathrm{s}$ and $\mathrm{kPa}$ are not synonymous. The relationship between SWS and Young's modulus is $\mathrm{E}=3 \rho \mathrm{V}^{2}$, in which $\mathrm{E}$ represents Young's modulus, 3 is a constant related to Poisson's ratio for strain, $\rho$ is tissue density (assumed to be $1 \mathrm{~g} / \mathrm{cm}^{3}$ ), and $\mathrm{V}$ is the shear wave speed (16). A faster speed is associated with lower elasticity and higher stiffness, and vice versa (26). The circular region of interest (ROI) with a diameter of $3 \mathrm{~mm}$ was chosen for isolated muscle measurements and $1 \mathrm{~mm}$ for the skin and superficial subcutaneous fascia measurements. The Aixplorer system penetration (Pen) condition was chosen during SWS measurement, which could change the frequency in order to increase the sound wave propagation distance when measuring tissue at different depths. During shear wave elastography, many ultrasound artifacts are encountered, such as strip-shaped "fence-like" artifacts, a 
signal void area, or an area of very high/low stiffness in the elastogram. These artifacts should be avoided during SWS measurement.

\section{Shear wave elastography acquisition}

Shear wave elastography procedures were performed independently by operators $\mathrm{A}, \mathrm{B}$, and $\mathrm{C}$, who were 1 senior and 2 junior sonographers with 10 and 3 years of experience, respectively. All operators were trained on a minimum of 10 muscle specimens before the experiment. The probe was positioned in a longitudinal orientation (along the fibers) according to the orientation of the fibers. The readings were repeated 3 times for each acquisition method, and the probe was removed and replaced each time.

\section{Ex-vivo muscle}

When measuring isolated muscles in vitro, 7 different depths $(0.5,1,2,3,4,5$, and $6 \mathrm{~cm})$ were selected to evaluate the effect of acquisition depth on shear wave elastography. The depth from the surface to the center of the ROI was measured before measuring the SWS. The muscle samples were placed between 2 fixators without applying any pressure to maintain their shapes during the examination. The deep and superficial tissues were tested while placing the ROI away from the edge of the muscle to prevent any possible influence on SWS measurements. All 3 operators were involved in these measurements.

Readings were acquired using 5 different couplant thicknesses, including 1, 2, 3, 4, and $5 \mathrm{~mm}$, within the isolated muscle in vitro. The thickness of the couplant was checked on the B-mode image before the acquisition. Bubbles were not allowed in the couplant during measurement. Light direct contact, which ensured that the probe was directly in contact with the tissue using the minimal couplant and without deforming the superficial tissue, was also selected as the minimal probe pressure. All 3 operators participated in the measurement. In addition, two probe pressures ( 1.5 and $3.0 \mathrm{kPa}$ ) were used by pressing the muscle manually, which was performed by operator A. The pressure was quantified by placing an electronic scale under the isolated muscle.

\section{Skin and subcutaneous superficial fascia of the human body}

To investigate whether the couplant thickness affected the
SWS when the acquisition depth was less than $0.5 \mathrm{~cm}$, we measured the skin and subcutaneous superficial fascia from the front of the bilateral forearm, $10 \mathrm{~cm}$ below the elbow, from a total of 26 locations of volunteers within a depth of $0.4 \mathrm{~cm}(0.1,0.2,0.3$, and $0.4 \mathrm{~cm}$; Figure $1 B)$. The depth from the skin surface to the center of the ROI was measured before the SWS measurement. We then tested 8 different couplant thicknesses, including 1, 2, 3, 4, 5, 10, 15, and $20 \mathrm{~mm}$, along with the light direct contact between the probe and skin surface.

\section{Reproducibility}

Readings were repeated 3 times for each combination of depth $(1-6 \mathrm{~cm})$ and couplant thickness $(1-5 \mathrm{~mm}$, light direct contact) by each operator within muscles in vitro. According to ultrasound guidance, the measurement position of each sample was marked on the isolated muscle using a surgical marker. When operator A completed the measurement, operators B and $\mathrm{C}$ repeated the same. The total measurement time of each sample was completed within 1 hour to avoid variations in muscle elasticity due to physical changes.

\section{Data and statistics}

SPSS software (version 22.0) was used for statistical analysis. All data are presented as mean \pm standard deviation (SD). A $\mathrm{P}$ value $<0.05$ was considered statistically significant. Mean and SD SWS was calculated for each operator.

Analysis of variance and Kruskal-Wallis test were used to compare SWS between different acquisition depths and different pressures from the probe and couplant. The post hoc analysis, which compares the SWS of different depths and pressure, was performed using the Bonferroniadjusted $\mathrm{P}$ value of 0.017 (obtained by dividing 0.05 by 3 ). To evaluate the trend between acquisition depths and SWS, we performed simple linear regression. The intraclass correlation coefficient (ICC) was used to assess the reproducibility of the measurements, and the ICC value was interpreted as follows: $0.00-0.20$ for poor agreement, 0.21-0.40 for fair agreement, $0.41-0.60$ for moderate agreement, $0.61-0.80$ for substantial agreement, and $>0.80$ for an almost perfect agreement (26). The reproducibility of the mean values between different operators was evaluated by ICC and $95 \%$ confidence interval (CI). 
Table 1 SWS results of 3 operators at different acquisition depths for ex-vivo study

\begin{tabular}{|c|c|c|c|c|c|c|c|c|}
\hline Operators & \multicolumn{7}{|c|}{$\mathrm{SWS}(\mathrm{M} \pm \mathrm{SD})(\mathrm{m} / \mathrm{s})$} & $\mathrm{P}$ \\
\hline$A$ & $3.30 \pm 0.42$ & $3.42 \pm 0.40$ & $3.56 \pm 0.40$ & $3.77 \pm 0.49$ & $4.33 \pm 0.51$ & $5.58 \pm 0.38$ & NA & $<0.001$ \\
\hline $\mathrm{B}$ & $3.33 \pm 0.45$ & $3.45 \pm 0.40$ & $3.57 \pm 0.43$ & $3.75 \pm 0.46$ & $4.30 \pm 0.56$ & $5.32 \pm 0.59$ & NA & $<0.001$ \\
\hline $\mathrm{C}$ & $3.20 \pm 0.44$ & $3.39 \pm 0.44$ & $3.64 \pm 0.44$ & $3.94 \pm 0.51$ & $4.55 \pm 0.60$ & $5.42 \pm 0.77$ & NA & $<0.001$ \\
\hline
\end{tabular}

SWS, shear wave speed; $\mathrm{M} \pm \mathrm{SD}$, mean \pm standard deviation; NA, not applicable.

\section{Results}

\section{Comparison of SWS at different acquisition depths}

The mean SWS was significantly different at various acquisition depths $(\mathrm{P}<0.001)$ regardless of the couplant thickness within the muscles. The SWS at a depth of $6 \mathrm{~cm}$ was not available. Table 1 lists the mean values and standard deviations of the SWS results of the 3 operators at different acquisition depths. Figure 2 indicates an increase in the SWS with increasing acquisition depth. The SWS increased significantly when the depth reached $4 \mathrm{~cm}$. The mean SWS of different couplant thicknesses was primarily linearly related to the depth when the depth was not more than $3 \mathrm{~cm}$, and a linear model of SWS at different depths was used to fit the variation, as shown in Figure 2B,D,F. The fitting line was regarded as the ideal relationship between SWS and depth. The ideal SWS values of 4 and $5 \mathrm{~cm}$ were calculated according to the fitting line, and the percentage error values of the experimental value compared with the ideal value are presented in Figure 3.

\section{Comparison of SWS with different pressure applied by probe and couplant}

For the three operators, SWS measured at the same depth was not statistically different among the different couplant conditions (1-5 mm, $\mathrm{P} \geq 0.05$ ) for muscles, as listed in Table 2 . Concerning different couplant thicknesses, the coefficient of variation (CV) had little fluctuation (Table 2). However, when manually applying pressure to the muscles (1.5 and $3.0 \mathrm{kPa}$ ), SWS was higher (Figure 4) and significantly different (Table 3) when the acquisition depth was $0.5-5 \mathrm{~cm}$.

The SWS of the skin and subcutaneous tissues with a different amount of couplant at the acquisition depth of no more than $0.4 \mathrm{~cm}$ is shown in Table 4 . When the acquisition depths were no more than $0.3 \mathrm{~cm}$, the SWS varied according to couplant thickness $(\mathrm{P}<0.05)$. When the
SWS values were acquired at a depth of 0.1 to $0.2 \mathrm{~cm}$, post hoc tests revealed that the SWS with couplant thickness of 10 to $20 \mathrm{~mm}$ was significantly different compared with that of other couplant thicknesses $(1-5 \mathrm{~mm} ; \mathrm{P}<0.05)$. When the acquisition depth increased to $0.3 \mathrm{~cm}$, the SWS was significantly different between the $20 \mathrm{~mm}$ and the other couplant thicknesses, whereas the SWS did not demonstrate a significant difference with different couplant thicknesses at a depth of $0.4 \mathrm{~cm}(\mathrm{P}>0.05)$. In addition, in cases where the acquisition depth was $0.1-0.2 \mathrm{~cm}$, post hoc tests revealed that the SWS acquired with the minimal probe pressure (light direct contact) was significantly different from that acquired with an amount of couplant thickness $(1-5 \mathrm{~mm}$; $\mathrm{P}<0.05)$.

\section{Reproducibility of SWS}

The degree of agreement of intra-operator reproducibility was satisfactory (ICC, $0.81-0.95$ ) for 29 of the 36 combined conditions (Table 5). When the acquisition depth was $5 \mathrm{~cm}$, the degree of agreement was fair to moderate (ICC, 0.20 0.60; Table 5). As listed in Table 6, the degree of agreement of inter-operator reproducibility was substantial to almost perfect (ICC >0.60) at the acquisition depth of 0.5 to $3 \mathrm{~cm}$, whereas the degree of agreement was fair to moderate (ICC, $0.20-0.60$ ) when the acquisition depth increased to $5 \mathrm{~cm}$.

\section{Discussion}

Shear wave elastography is a promising technology, and its use has progressively increased in routine musculoskeletal tissue examinations. The SWS acquisition method is still controversial, and few studies have tested the same factors using muscles in vitro. The sample number of a previous study was small with limited data on superficial soft tissue, daily use of couplant, and the intra- and interoperator reproducibility (27). The present study focused on 

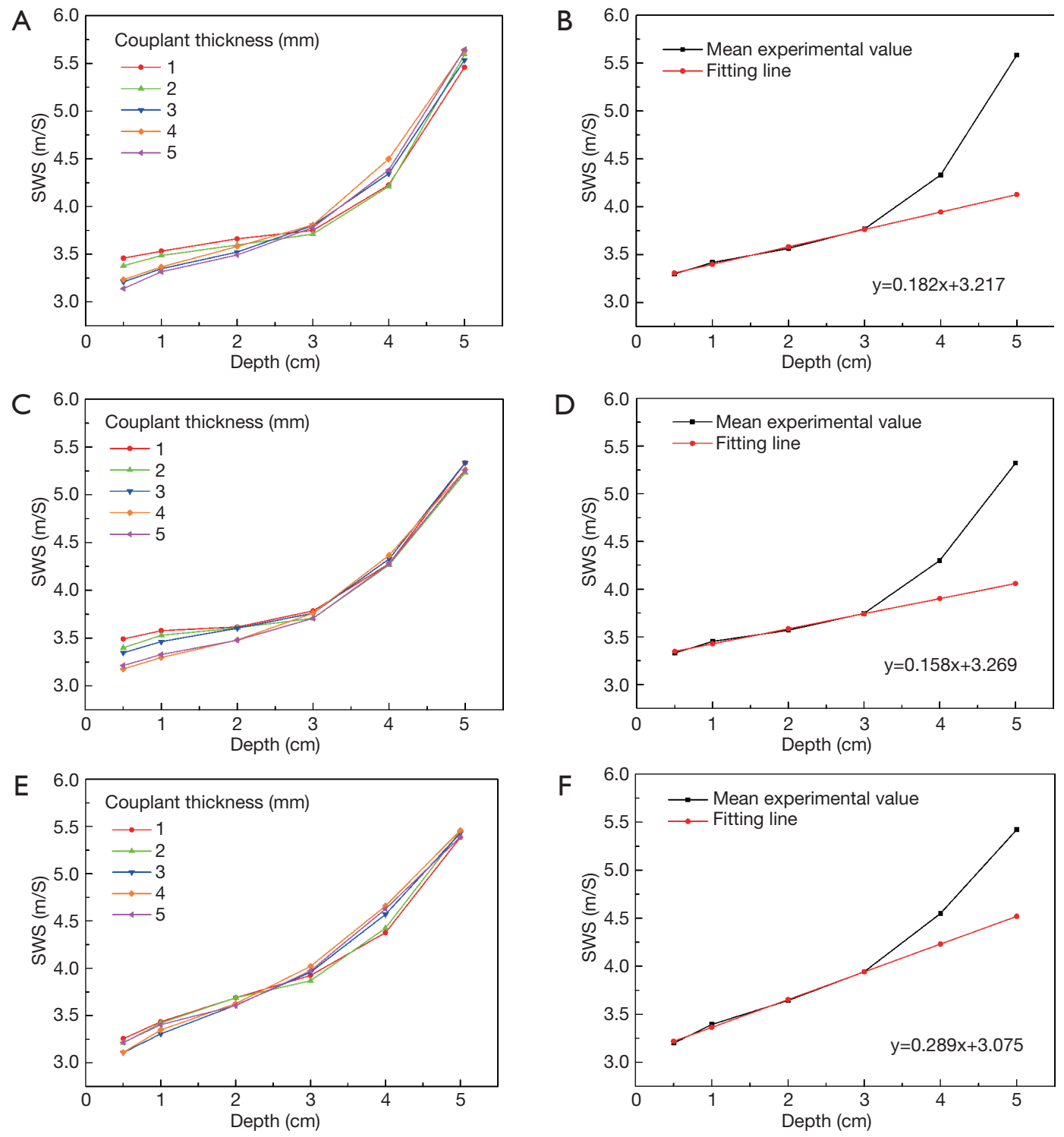

Figure 2 Effect of the acquisition depth on the SWS with different couplant thicknesses (1-5 mm) of ex-vivo study: (A) operator A, (C) operator B, and (E) operator C. Mean SWS of different couplant thicknesses and fitting line: (B) operator A, (D) operator B, and (F) operator C.

evaluating the influencing factors that may be essential for the standardization of muscle evaluation using shear wave elastography.

The first part of the present study investigated the influence of acquisition depth on SWS within muscles in the present system with the linear probe. The results presented significant differences between SWS at various acquisition depths, from $0.5 \mathrm{~cm}$ to $5.0 \mathrm{~cm}$ for muscles (Table 1). In cases where the acquisition depths were less than $3 \mathrm{~cm}$, the SWS increased linearly with increasing depth. The SWS increased more obviously when the acquisition depth was deeper than $3 \mathrm{~cm}$ (Figure 2). However, when the depth increased to $6 \mathrm{~cm}$, the shear wave failed to be detected. However, this was true only for the present linear probe (SL10-2 linear probe). When measuring deeper tissue ( $\geq 6 \mathrm{~cm}$ ), it may be feasible to use a lower frequency convex probe. Several studies have revealed that the acquisition depth significantly influences the SWS. Carpenter et al. examined the effect of depth on the SWS of muscle in a healthy cohort and reported that the SWS 
for superficial acquisitions was significantly lower than that for deep acquisitions with depth readings no more than $2.5 \mathrm{~cm}$ (28). Rominger et al. studied the effects of depth on SWS in vitro and found an increase in the mean SWS in muscle by progressively the increasing depth using a linear probe (27). In this study, the SWS also exhibited an increasing trend with the increase in acquisition depths, contrary to the findings reported by Alfuraih et al. (21) and Rominger et al. (27). These variations among the results could be associated with differences in the equipment used and the muscles investigated.

Moreover, a previous review reported that a deeper acquisition depth was responsible for an attenuation effect that disturbed the shear wave collection and showed a signal void

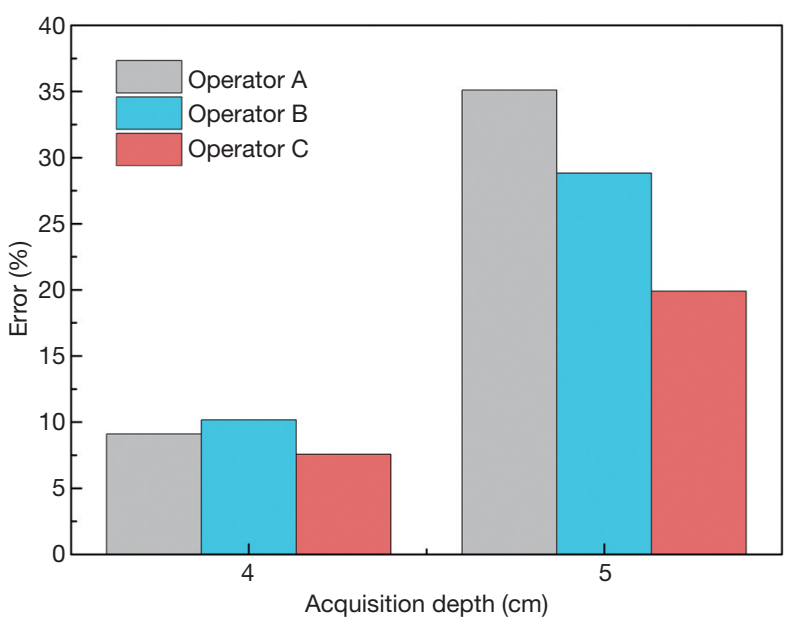

Figure 3 Percentage error at depths of $4 \mathrm{~cm}$ and $5 \mathrm{~cm}$ for ex-vivo study. or areas of very high/low stiffness in the elastic image (24). The results in Figure 2 also indicate that the linear relationship between the depth and the SWS disappeared when the depth reached $4 \mathrm{~cm}$ or higher (i.e., the measured SWS would probably be inaccurate). A previous investigation reported that the measurements were not feasible for depths of more than $5 \mathrm{~cm}$ for muscles (27). The power of the acoustic radiation force impulse (push pulse) eventually diminished at larger depths $(5.0 \mathrm{~cm})$, rendering the generated shear waves too weak to be detected accurately $(21,29,30)$. When the depth was 4 and $5 \mathrm{~cm}$, the percentage error was theoretically $7.57-10.26$ and 19.91-35.11, respectively. To our knowledge, there is no cutoff value of acceptable error in shear wave elastography. Therefore, when measuring the SWS of muscles, the suitable measurement depth is recommended to be within $3 \mathrm{~cm}$, and going beyond $(4-5 \mathrm{~cm})$ would not be feasible or ideal in the present conditions and system.

With regards to the pressure applied by the couplant or probe within the muscle, our results suggest that using a specific amount of couplant $(1-5 \mathrm{~mm})$ may be more applicable. Carpenter et al. studied the effect of probe pressure on muscle by using normal probe contact and axial stress and pointed out that the SWS with preload was significantly higher (28). Kot et al. carried out a similar study and reported a significant difference when a different pressure of the transducer was applied (31). Taken together, the above studies indicate that probe pressure affects SWS, which is in line with our result; however, evidence for the most suitable method remains insufficient. As far as we know, soft tissue is a deformable tissue; therefore, the SWS of soft tissue is sensitive to pressure. SWS changes in the

Table 2 SWS results of 3 operators with different couplant thicknesses for ex-vivo study

\begin{tabular}{|c|c|c|c|c|c|c|}
\hline $\begin{array}{l}\text { Couplant thickness } \\
(\mathrm{mm})\end{array}$ & \multicolumn{2}{|l|}{$A$} & \multicolumn{2}{|l|}{ B } & \multicolumn{2}{|l|}{ C } \\
\hline Light direct contact & $4.01 \pm 0.88$ & 21.9 & $4.01 \pm 0.90$ & 22.4 & $4.06 \pm 0.94$ & 23.2 \\
\hline 1 & $4.01 \pm 0.80$ & 20.0 & $4.01 \pm 0.76$ & 19.0 & $4.01 \pm 0.88$ & 21.9 \\
\hline 2 & $4.00 \pm 0.86$ & 21.5 & $3.96 \pm 0.82$ & 20.7 & $4.01 \pm 0.91$ & 22.7 \\
\hline 4 & $4.02 \pm 0.96$ & 23.9 & $3.89 \pm 0.87$ & 22.4 & $4.04 \pm 1.01$ & 25.0 \\
\hline 5 & $3.96 \pm 0.96$ & 24.2 & $3.88 \pm 0.85$ & 21.9 & $4.04 \pm 0.93$ & 23.0 \\
\hline$P$ & \multicolumn{2}{|c|}{$0.98(>0.05)$} & \multicolumn{2}{|c|}{$0.60(>0.05)$} & \multicolumn{2}{|c|}{$0.99(>0.05)$} \\
\hline
\end{tabular}

$\mathrm{A}, \mathrm{B}$, and $\mathrm{C}$ were the 3 operators; $\mathrm{M} \pm \mathrm{SD}$ indicates mean \pm standard deviation; SWS, shear wave speed; NA, not applicable. 

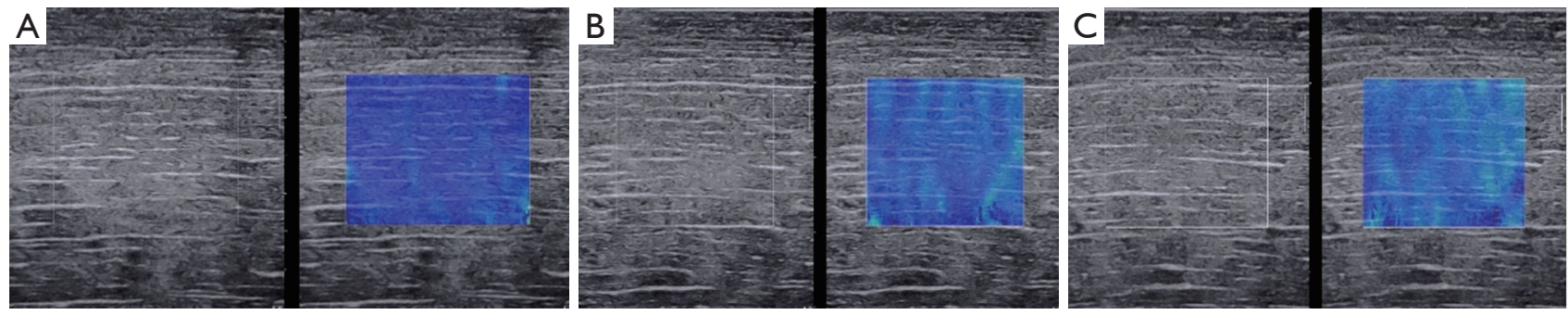

Figure 4 Shear wave elastic images under different pressures for ex-vivo study (minimal probe pressure, $1.5 \mathrm{kPa}$, and $3.0 \mathrm{kPa}$ ).

Table 3 SWS results of operator A under different pressures from the couplant and probe for $e x$-vivo study

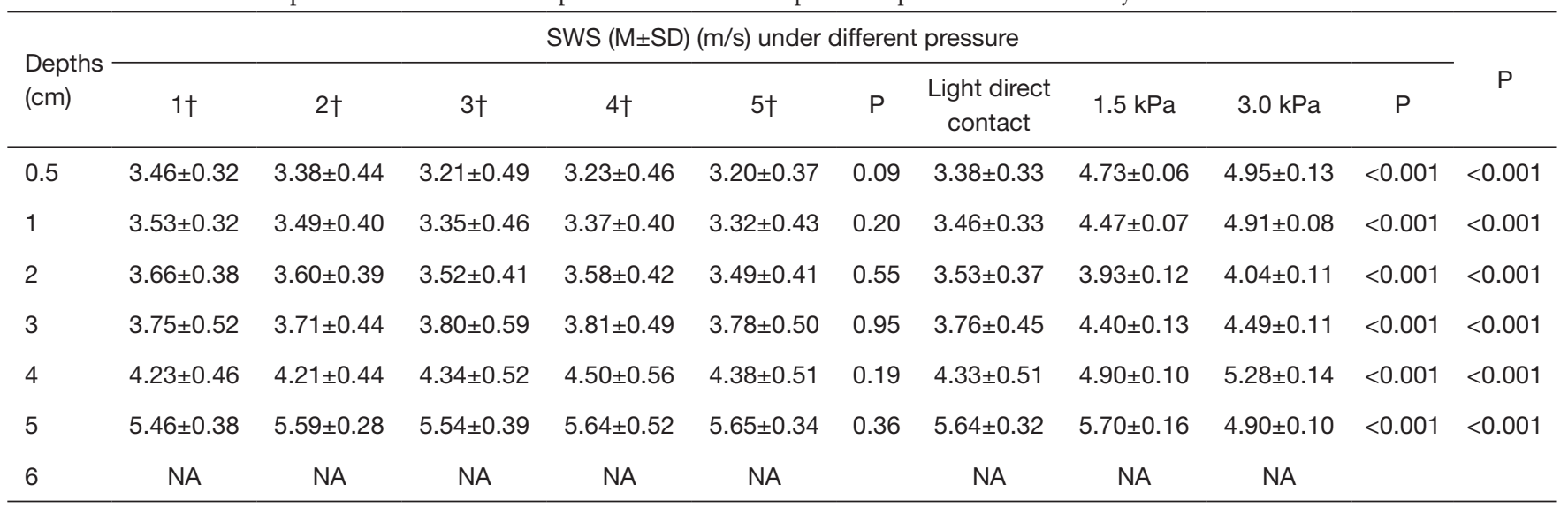

$\dagger$, couplant thickness $(\mathrm{mm}) . \mathrm{M} \pm \mathrm{SD}$, mean \pm standard deviation; SWS, shear wave speed.

Table 4 SWS results of skin and the subcutaneous superficial fascia for in-vivo study

\begin{tabular}{lccccccccccc}
\hline \multirow{2}{*}{$\begin{array}{l}\text { Depth } \\
(\mathrm{cm})\end{array}$} & $\begin{array}{c}\text { Light direct } \\
\text { contact }\end{array}$ & $1 \dagger$ & $2 \dagger$ & $3 \dagger$ & $4 \dagger$ & $5 \dagger$ & $10 \dagger$ & $15 \dagger$ & $20 \dagger$ & $P$ \\
\hline 0.1 & $3.06 \pm 0.44$ & $2.67 \pm 0.51$ & $2.57 \pm 0.58$ & $2.45 \pm 0.55$ & $2.48 \pm 0.53$ & $2.36 \pm 0.42$ & $3.10 \pm 1.02$ & $2.96 \pm 0.81$ & $3.06 \pm 0.85$ & $<0.001$ \\
0.2 & $2.97 \pm 0.57$ & $2.63 \pm 0.52$ & $2.51 \pm 0.49$ & $2.50 \pm 0.55$ & $2.53 \pm 0.58$ & $2.80 \pm 0.15$ & $3.20 \pm 0.79$ & $3.05 \pm 0.49$ & $3.23 \pm 0.65$ & $<0.001$ \\
0.3 & $3.30 \pm 1.03$ & $2.82 \pm 0.91$ & $2.83 \pm 0.94$ & $2.82 \pm 1.14$ & $2.69 \pm 0.97$ & $2.71 \pm 0.98$ & $3.10 \pm 0.70$ & $2.92 \pm 0.40$ & $3.50 \pm 0.70$ & 0.02 \\
0.4 & $2.99 \pm 1.05$ & $3.05 \pm 0.77$ & $3.03 \pm 0.87$ & $2.88 \pm 0.94$ & $2.96 \pm 1.00$ & $2.95 \pm 0.99$ & $3.08 \pm 0.68$ & $2.78 \pm 0.38$ & $3.43 \pm 0.80$ & 0.44 \\
\hline
\end{tabular}

$\dagger$, couplant thickness $(\mathrm{mm}) . \mathrm{M} \pm \mathrm{SD}$, mean \pm standard deviation; SWS, shear wave speed.

conditions of high pressure and may consequently change the tissue structure or shape. Therefore, the pressure applied to the tissue should be as low as possible. The couplant used during the shear wave elastography examination will exert a certain amount of pressure on the tissue. However, the pressure generated by $5 \mathrm{~mm}$ couplant was not high enough to influence the elasticity of the muscle tissue (depth $\geq 0.5 \mathrm{~cm}$ ). We investigated the feasible couplant thickness and probe pressure on muscle that would also be frequently usable and practical, and generated reproducible results in clinical settings. The results demonstrated that there was no difference among the SWS when the couplant thickness varied from 1 to $5 \mathrm{~mm}$, but there was a significant difference when applying pressure manually $(1.5$ and $3.0 \mathrm{kPa})$. As a result, in the present conditions and system, an amount of couplant should be applied onto the tissue surface instead of applying the pressure manually through the probe.

The present study is possibly the first to purposefully 
Table 5 Reproducibility of different depths and couplant combinations demonstrated as intraoperator correlation coefficient within (intra) operator A for ex-vivo study

\begin{tabular}{lcccccc}
\hline $\begin{array}{l}\text { Couplant thickness } \\
(\mathrm{mm})\end{array}$ & \multicolumn{5}{c}{ Acquisition depth (cm), ICC (95\% CI) } \\
\cline { 2 - 6 } & 0.5 & 1 & 2 & 3 & 4 & 5 \\
\hline Light direct contact & $0.81(0.67-0.90)$ & $0.81(0.68-0.90)$ & $0.86(0.76-0.93)$ & $0.88(0.79-0.94)$ & $0.82(0.70-0.91)$ & $0.34(0.11-0.58)$ \\
1 & $0.85(0.73-0.92)$ & $0.83(0.71-0.91)$ & $0.87(0.77-0.93)$ & $0.94(0.89-0.97)$ & $0.79(0.65-0.89)$ & $0.47(0.24-0.68)$ \\
2 & $0.94(0.89-0.97)$ & $0.92(0.85-0.96)$ & $0.90(0.83-0.95)$ & $0.86(0.75-0.93)$ & $0.84(0.72-0.92)$ & $0.27(0.05-0.52)$ \\
3 & $0.93(0.87-0.96)$ & $0.91(0.80-0.96)$ & $0.84(0.72-0.92)$ & $0.95(0.92-0.98)$ & $0.89(0.80-0.94)$ & $0.25(0.02-0.50)$ \\
4 & $0.92(0.85-0.96)$ & $0.90(0.83-0.95)$ & $0.86(0.75-0.93)$ & $0.91(0.83-0.95)$ & $0.84(0.72-0.92)$ & $0.37(0.13-0.60)$ \\
5 & $0.91(0.83-0.95)$ & $0.87(0.78-0.94)$ & $0.82(0.70-0.91)$ & $0.90(0.82-0.95)$ & $0.86(0.75-0.93)$ & $0.53(0.30-0.72)$ \\
\hline
\end{tabular}

Table 6 Reproducibility of different depths and couplant combinations demonstrated as interoperator correlation coefficient among the 3 operators for ex-vivo study

\begin{tabular}{lcccccc}
\hline \multirow{2}{*}{\begin{tabular}{l} 
Couplant thickness $(\mathrm{mm})$ \\
\cline { 2 - 6 }
\end{tabular}} & 0.5 & 1 & 2 & 3 & 4 & 5 \\
\hline Light direct contact & $0.65(0.32-0.83)$ & $0.74(0.50-0.87)$ & $0.81(0.64-0.91)$ & $0.72(0.46-0.86)$ & $0.40(0-0.71)$ & $0.39(0-0.70)$ \\
1 & $0.69(0.40-0.85)$ & $0.79(0.60-0.90)$ & $0.88(0.77-0.94)$ & $0.83(0.67-0.92)$ & $0.49(0.02-0.76)$ & $0.35(0-0.69)$ \\
2 & $0.78(0.57-0.89)$ & $0.81(0.63-0.91)$ & $0.89(0.79-0.95)$ & $0.86(0.74-0.93)$ & $0.60(0.24-0.81)$ & $0.48(0-0.75)$ \\
3 & $0.77(0.55-0.89)$ & $0.20(0-0.62)$ & $0.80(0.61-0.90)$ & $0.85(0.70-0.93)$ & $0.32(0-0.67)$ & $0.35(0-0.69)$ \\
4 & $0.75(0.52-0.88)$ & $0.76(0.54-0.89)$ & $0.83(0.68-0.92)$ & $0.74(0.49-0.87)$ & $0.42(0-0.72)$ & $0.26(0-0.64)$ \\
5 & $0.78(0.58-0.90)$ & $0.84(0.70-0.92)$ & $0.87(0.75-0.94)$ & $0.85(0.71-0.93)$ & $0.38(0-0.70)$ & $0.52(0.08-0.77)$ \\
\hline
\end{tabular}

investigate the effect of the amount of couplant on SWS of skin and subcutaneous superficial fascia. In an ex vivo study, Rominger et al. studied the influence of manually increasing probe pressure by applying 0 to 3,000 $\mathrm{g}$ weight to the muscle tissue surface and found an increase in SWS. Therefore, they recommended using minimal pressure to ensure light contact with body skin during measurement (27). Another study compared the minimal probe load with the use of a standoff gel layer within muscle, and the authors supported placing the probe in direct contact with the skin without standoff gel (21). However, these findings may not be generalized to particularly superficial tissues such as the skin and superficial tissue. This was expected to be improved by adding a suitable amount of couplant without applying too much pressure. Our study indicated that it was not suitable to apply a couplant of more than $10 \mathrm{~mm}$ or to place the probe in slight contact with the skin when the tested tissue depth is within $0.2 \mathrm{~cm}$. The study also demonstrated that it is not acceptable to use the couplant with more than $20 \mathrm{~mm}$ when the acquisition depth reached
$0.3 \mathrm{~cm}$. Considering the possible differences in elasticity and measurement conditions, these findings may not be directly or accurately generalizable to all patients or to all skin and subcutaneous tissues of the human body, and further studies are needed to confirm their applicability. Nevertheless, our results warrant future studies on the use of shear wave elastography on skin.

In this study, different combinations of acquisition depths and couplant thicknesses were used to assess their reliability on muscles in vitro. This was done by testing the intra- and inter-operator reproducibility (Tables 5,6). Typically, it is recommended to take an average of 3 measurements per test to ensure accuracy $(29,30)$. This study briefly compared the agreement between 3 repeated acquisitions and 3 operators for each combination of acquisition depth and couplant thickness. The results showed that the intra- and inter-agreement degree observed at the $5 \mathrm{~cm}$ acquisition depth was not satisfactory, which might have resulted from the acoustic attenuation that led to an uneven distribution of SWS. However, in cases where the acquisition depth 
was $\leq 4 \mathrm{~cm}$, the consistency of intra- and inter-operator reproducibility was nearly perfect regardless of couplant thickness. This suggests that the SWS measurement had good inter- and intra-operator reproducibility as long as the acquisition depth is $\leq 4 \mathrm{~cm}$, and the couplant thickness was no more than $5 \mathrm{~mm}$ under present conditions.

Our study has some limitations. First, the sample size was not large enough. Second, isolated pork muscles were used and successively measured by different operators, but the tissue may have decomposed over time, and the elasticity might have changed. Moreover, the temperature of the ex vivo pork muscles was different from the in vivo temperature. However, this ex vivo study remains meaningful for controlling the influence of the living body to demonstrate the effect of target factors. Finally, the findings acquired from the skin and subcutaneous tissue might need further investigation to confirm their applicability in other regions of the body or patients with different BMIs.

\section{Conclusions}

In the present system and study conditions, the results revealed considerable variations in SWS due to the acquisition depths. Muscle SWS readings acquired at depths of no more than $3 \mathrm{~cm}$ using an amount of couplant may produce relatively accurate results. In cases where the acquisition depth was not more than $0.2 \mathrm{~cm}$, light direct contact of the probe or applying couplant more than $10 \mathrm{~mm}$ may not be recommended for skin and subcutaneous tissue measurements. Inter- and intra-operator reproducibility was excellent, and was even better when the acquisition depths were 0.5 to $4 \mathrm{~cm}$ as compared to $5 \mathrm{~cm}$.

\section{Acknowledgments}

We thank all participants and volunteers for their cooperation and efforts.

Funding: This work was supported by funding from the National Natural Science Foundation of China (No. 81571684).

\section{Footnote}

Conflicts of Interest: The authors have no conflicts of interest to declare.

Ethical Statement: The study was approved by the
Institutional Ethics Board of Peking University People's Hospital, and written informed consent was obtained from all patients.

Open Access Statement: This is an Open Access article distributed in accordance with the Creative Commons Attribution-NonCommercial-NoDerivs 4.0 International License (CC BY-NC-ND 4.0), which permits the noncommercial replication and distribution of the article with the strict proviso that no changes or edits are made and the original work is properly cited (including links to both the formal publication through the relevant DOI and the license). See: https://creativecommons.org/licenses/by-nc-nd/4.0/.

\section{References}

1. Shin HJ, Kim MJ, Kim HY, Roh YH, Lee MJ. Comparison of shear wave velocities on ultrasound elastography between different machines, transducers, and acquisition depths: a phantom study. Eur Radiol 2016;26:3361-7.

2. Ophir J, Céspedes I, Ponnekanti H, Yazdi Y, Li X. Elastography: a quantitative method for imaging the elasticity of biological tissues. Ultrason Imaging 1991;13:111-34.

3. Gennisson JL, Deffieux T, Fink M, Tanter M. Ultrasound elastography: Principles and techniques. Diagn Interv Imaging 2013;94:487-95.

4. Jeong WK, Lim HK, Lee HK, Jo JM, Kim Y. Principles and clinical application of ultrasound elastography for diffuse liver disease. Ultrasonography 2014;33:149-60.

5. Park MK, Jo J, Kwon H, Cho JH, Oh JY, Noh MH, Nam KJ. Usefulness of acoustic radiation force impulse elastography in the differential diagnosis of benign and malignant solid pancreatic lesions. Ultrasonography 2014;33:26-33.

6. Vachutka J, Sedlackova Z, Furst T, Herman M, Herman J, Salzman R, Dolezal L. Evaluation of the Effect of Tissue Compression on the Results of Shear Wave Elastography Measurements. Ultrason Imaging 2018;40:380-93.

7. Suvannarerg V, Chitchumnong P, Apiwat W, Lertdamrongdej L, Tretipwanit N, Pisarnturakit P, Sitthinamsuwan P, Thiravit S, Muangsomboon K, Korpraphong P. Diagnostic performance of qualitative and quantitative shear wave elastography in differentiating malignant from benign breast masses, and association with the histological prognostic factors. Quant Imaging Med Surg 2019;9:386-98.

8. He Y, Xiang X, Zhu BH, Qiu L. Shear wave elastography 
evaluation of the median and tibial nerve in diabetic peripheral neuropathy. Quant Imaging Med Surg 2019;9:273-82.

9. Barr RG, Nakashima K, Amy D, Cosgrove D, Farrokh A, Schafer F, Bamber JC, Castera L, Choi BI, Chou YH, Dietrich CF, Ding H, Ferraioli G, Filice C, FriedrichRust M, Hall TJ, Nightingale KR, Palmeri ML, Shiina T, Suzuki S, Sporea I, Wilson S, Kudo M. WFUMB Guidelines and Recommendations for Clinical Use of Ultrasound Elastography: Part 2: Breast. Ultrasound Med Biol 2015;41:1148-60.

10. Cosgrove D, Barr R, Bojunga J, Cantisani V, Chammas MC, Dighe M, Vinayak S, Xu JM, Dietrich CF. WFUMB Guidelines and Recommendations on the Clinical Use of Ultrasound Elastography: Part 4. Thyroid. Ultrasound Med Biol 2017;43:4-26.

11. Ferraioli G, Filice C, Castera L, Choi BI, Sporea I, Wilson SR, Cosgrove D, Dietrich CF, Amy D, Bamber JC, Barr R, Chou YH, Ding H, Farrokh A, FriedrichRust M, Hall TJ, Nakashima K, Nightingale KR, Palmeri ML, Schafer F, Shiina T, Suzuki S, Kudo M. WFUMB Guidelines and Recommendations for Clinical Use of Ultrasound Elastography: Part 3: Liver. Ultrasound Med Biol 2015;41:1161-79.

12. Barr RG, Cosgrove D, Brock M, Cantisani V, Correas JM, Postema AW, Salomon G, Tsutsumi M, Xu HX, Dietrich CF. WFUMB Guidelines and Recommendations on the Clinical Use of Ultrasound Elastography: Part 5. Prostate. Ultrasound Med Biol 2017;43:27-48.

13. Ryu J, Jeong WK. Current status of musculoskeletal application of shear wave elastography. Ultrasonography 2017;36:185-97.

14. Levinson SF, Shinagawa M, Sato T. Sonoelastic determination of human skeletal muscle elasticity. J Biomech 1995;28:1145-54.

15. Taljanovic MS, Gimber LH, Becker GW, Latt LD, Klauser AS, Melville DM, Gao L, Witte RS. ShearWave Elastography: Basic Physics and Musculoskeletal Applications. Radiographics 2017;37:855-70.

16. Hall TJ, Milkowski A, Garra, Carson P, Palmeri M, Nightingale K, Lynch T, Alturki A, Andre M, Audiere S, Bamber J, Barr R, Bercoff J, Bernal M, Brum J, Huan Wee C, Shigao C, Cohen-Bacrie C, Couade M, Daniels A, DeWall R, Dillman J, Ehman R, Franchi-Abella S, Fromageau J, Gennisson JL, Henry JP, Ivancevich N, Kalin J, Kohn S, Kugel J, Ken L, Liu N, Loupas T, Mazernik J, McAleavey S, Miette V, Metz S, Morel B, Nelson T, Nordberg E, Oudry J, Padwal M, Rouze N,
Samir A, Sandrin L, Schaccitti J, Schmitt C, Shamdasani V, Pehngfei S, Switalski P, Wang M, Wear K, Hua X, Heng Z. RSNA/QIBA: Shear wave speed as a biomarker for liver fibrosis staging. Ultrasonics Symposium (IUS), 2013 IEEE International. 2013:397-400.

17. Carlsen JF, Pedersen MR, Ewertsen C, Săftoiu A, Lönn L, Rafaelsen SR, Nielsen MB. A comparative study of strain and shear-wave elastography in an elasticity phantom. AJR Am J Roentgenol 2015;204:W236-42.

18. Cortez CD, Hermitte L, Ramain A, Mesmann C, Lefort T, Pialat JB. Ultrasound shear wave velocity in skeletal muscle: A reproducibility study. Diagn Interv Imaging 2016;97:71-9.

19. Wang CZ, Zheng J, Huang ZP, Xiao Y, Song D, Zeng J, Zheng HR, Zheng RQ. Influence of measurement depth on the stiffness assessment of healthy liver with real-time shear wave elastography. Ultrasound Med Biol 2014;40:461-9.

20. Tozaki M, Saito M, Joo C, Yamaguchi M, Isobe S, Ogawa Y, Homma K, Fukuma E. Ultrasonographic tissue quantification of the breast using acoustic radiation force impulse technology: phantom study and clinical application. Jpn J Radiol 2011;29:598-603.

21. Alfuraih AM, O'Connor P, Hensor E, Tan AL, Emery P, Wakefield RJ. The effect of unit, depth, and probe load on the reliability of muscle shear wave elastography: Variables affecting reliability of SWE. J Clin Ultrasound 2018;46:108-15.

22. Lam AC, Pang SW, Ahuja AT, Bhatia KS. The influence of precompression on elasticity of thyroid nodules estimated by ultrasound shear wave elastography. Eur Radiol 2016;26:2845-52.

23. Ewertsen C, Carlsen JF, Christiansen IR, Jensen JA, Nielsen MB. Evaluation of healthy muscle tissue by strain and shear wave elastography - Dependency on depth and ROI position in relation to underlying bone. Ultrasonics 2016;71:127-33.

24. Creze M, Nordez A, Soubeyrand M, Rocher L, Maître $\mathrm{X}$, Bellin MF. Shear wave sonoelastography of skeletal muscle: basic principles, biomechanical concepts, clinical applications, and future perspectives. Skeletal Radiol 2018;47:457-71.

25. Lacourpaille L, Hug F, Bouillard K, Hogrel JY, Nordez A. Supersonic shear imaging provides a reliable measurement of resting muscle shear elastic modulus. Physiol Meas 2012;33:N19-28.

26. Alfuraih AM, O'Connor P, Tan AL, Hensor E, Emery P, Wakefield RJ. An investigation into the variability between 
different shear wave elastography systems in muscle.

Medical Ultrasonography 2017;19:392-400.

27. Rominger MB, Kälin P, Mastalerz M, Martini K, Klingmüller V, Sanabria S, Frauenfelder T. Influencing Factors of 2D Shear Wave Elastography of the Muscle - An Ex Vivo Animal Study. Ultrasound Int Open 2018;4:E54-60.

28. Carpenter EL, Lau HA, Kolodny EH, Adler RS. Skeletal Muscle in Healthy Subjects versus Those with GNERelated Myopathy: Evaluation with Shear-Wave US-A Pilot Study. Radiology 2015;277:546-54.

29. Cosgrove D, Barr R, Bojunga J, Cantisani V, Chammas MC, Dighe M, Vinayak S, Xu JM, Dietrich CF. WFUMB

Cite this article as: Wang $\mathrm{X}, \mathrm{Hu} \mathrm{Y,} \mathrm{Zhu} \mathrm{J,} \mathrm{Gao} \mathrm{J,} \mathrm{Chen}$ S, Liu F, Li W, Liu Y, Ariun B. Effect of acquisition depth and precompression from probe and couplant on shear wave elastography in soft tissue: an in vitro and in vivo study. Quant Imaging Med Surg 2020;10(3):754-765. doi: 10.21037/ qims.2020.01.15
Guidelines and Recommendations on the Clinical Use of Ultrasound Elastography: Part 4. Thyroid. Ultrasound Med Biol 2017;43:4-26.

30. Goertz RS, Amann K, Heide R, Bernatik T, Neurath MF, Strobel D. An abdominal and thyroid status with Acoustic Radiation Force Impulse Elastometry - A feasibility study: Acoustic Radiation Force Impulse Elastometry of human organs. Eur J Radiol 2011;80:e226-30.

31. Kot BC, Zhang ZJ, Lee AW, Leung VY, Fu SN. Elastic modulus of muscle and tendon with shear wave ultrasound elastography: variations with different technical settings. PLoS One 2012; 7:e44348. 